\title{
Aggravated Granuloma Annulare
}

National Cancer Institute

\section{Source}

National Cancer Institute. Aggravated Granuloma Annulare. NCI Thesaurus. Code C9259.

A chronic, inflammatory skin condition characterized by raised, ring shaped eruptions occurring singly or in groups; often on the tops of the hands, feet, elbows, and knees. It is commonly seen in children and young adults, and in women twice as much as men. 